\title{
The Use of Exergames in the Neurorehabilitation of People with Parkinson Disease: The Impact on Daily Life
}

Bianca Simone Zeigelboim ${ }^{10}$ Maria Renata José1® Maria Izabel Rodrigues Severiano ${ }^{2 \odot}$ Geslaine Janaína Bueno dos Santos ${ }^{2 ®}$ Helio Afonso Ghizoni Teive ${ }^{3(0)}$ Paulo Breno Noronha Liberalesso 4 Jair Mendes Marques ${ }^{10}$ Michéli Rodrigues da Rosa10 Rosane Sampaio Santos ${ }^{10}$ Jéssica Spricigo Malisky ${ }^{10}$

1 Department of Otoneurology, Universidade Tuiuti do Paraná (UTP), Curitiba, PR, Brazil

2 Department of Physical Therapy, Instituto Federal do Paraná, Address for correspondence Bianca Simone Zeigelboim, PhD, Rua Curitiba, PR, Brazil Gutemberg, 99, 9o andar, Curitiba, PR, 80.420.030, Brazil (e-mail: biancacwb@yahoo.com.br).

3 Department of Neurology, Hospital das Clínicas, Universidade

Federal do Paraná, Curitiba, PR, Brazil

4 Department of Neurology, Hospital Pequeno Príncipe, Curitiba, PR, Brazil

Int Arch Otorhinolaryngol 2021;25(1):e64-e70.

\begin{abstract}
Keywords

- Parkinson disease

- postural balance

- quality of life

- rehabilitation

- virtual reality

Introduction Parkinson disease (PD) is a progressive degeneration characterized by motor disorders, such as tremor, bradykinesia, stiffness and postural instability.

Objective To evaluate the independence, confidence and balance in the development of daily activities in patients with PD before and after rehabilitation.

Methods A descriptive, retrospective cross-sectional study was carried out with 16 patients (mean $57.6 \pm 18.7$ years), submitted to anamnesis, otolaryngological evaluation and vestibular assessment. The Vestibular Disorders Activities of Daily Living (VADL) and the Activities-Specific Balance Confidence (ABC) scales were applied before and after rehabilitation with virtual reality.

Results a) The instrumental subscale of the questionnaire showed statistically significant result ( $p=0.022 ; 95 \% \mathrm{Cl} 1.21 ; 2.21$ ) between the first and second assessments; $b$ ) The correlation between the questionnaires showed statistically significant result in the ambulation subscale $(p=0.011 ; 95 \% \mathrm{Cl}-0.85 ;-0.17)$ first and $(p=0.002,95 \% \mathrm{Cl}-0.88 ;-0.31)$ second assessments, and the functional subscale was only verified in the second assessment ( $p=0.011,95 \% \mathrm{Cl}-0.85 ;-0.17)$; and $c)$ The patients presented clinical improvement in the final assessment after rehabilitation with significant result for the tightrope walk ( $p=0.034$, $95 \% \mathrm{Cl}-12.5 ;-0.3)$ and ski slalom games $(p=0.005,95 \% \mathrm{Cl}-34.8 ;-6.6)$.

Conclusions Our results showed that the VADL and $A B C$ questionnaires, applied before and after rehabilitation, were important tools to measure the independence, confidence and balance while developing daily activities. The VADL and ABC questionnaires may effectively contribute to quantify the effect of the applied therapeutics and, consequently, its impact on the quality of life of patients with PD.
\end{abstract}

received

May 13, 2019

accepted

December 26, 2019

published online

April 24, 2020
DOI https://doi.org/ 10.1055/s-0040-1702973. ISSN 1809-9777.

\footnotetext{
(c) 2020. Fundação Otorrinolaringologia. All rights reserved. This is an open access article published by Thieme under the terms of the Creative Commons Attribution-NonDerivative-NonCommercial-License, permitting copying and reproduction so long as the original work is given appropriate credit. Contents may not be used for commercial purposes, or adapted, remixed, transformed or built upon. (https://creativecommons.org/ licenses/by-nc-nd/4.0/) Thieme Revinter Publicações Ltda., Rua do Matoso 170, Rio de Janeiro, RJ, CEP 20270-135, Brazil
} 


\section{Introduction}

Parkinson disease (PD) is a chronic disorder with progressive degeneration of the dopamine-producing cells in brain structures, including the substantia nigra. Its major symptoms are motor disorders, such as tremor, bradykinesia, stiffness and postural instability, ${ }^{1,2}$ causing functional decline, impairing the performance of activities of daily living (ADLs) and resulting in the reduction of physical independence and quality of life (QOL). ${ }^{3}$ Patients with PD have difficulties performing ADLs, specially tasks demanding coordination and balance. ${ }^{4,5}$

The elderly population, who have the greatest incidence of PD, present impaired balance. Postural instability occurs as the disease progresses, thus causing functional independence and, consequently, increasing the risk of falls. ${ }^{6,7}$ Although falls significantly affect the ADLs and the QOLof patients with $\mathrm{PD}$, the underlying neural mechanisms associated with frequent falls in PD patients are still unclear. ${ }^{7}$

Vestibular rehabilitation (VR) aims to modify the postural control system by means of specific, repetitive physical exercises under different conditions. It has been shown to act physiologically upon the vestibular system, being considered a therapeutic resource due to its performance proposal, based on the central mechanisms of neuroplasticity. ${ }^{8}$ The central nervous system (CNS) processes the information and responds to it by means of reflexes, the vestibulo-ocular reflex (VOR), which allows visual stabilization during the head movements, and the vestibulospinal reflex (VSR), which generates a body compensation movement in order to keep head and body stability, thus preventing falls. Neuroplasticity refers to the capacity of the CNS to modify some of its morphological and functional properties as a response to environmental changes. ${ }^{8}$

Imbalance and fear of falls may hinder the performance of ADLs, especially activities demanding fast head motions, and trunk and/or head flexions. ${ }^{9}$ Difficulties in carrying out ADLs can be assessed by means of formerly validated questionnaires. Among the existing instruments, we point out the Vestibular Disorders Activities of Daily Living (VADL) and the Activities-Specific Balance Confidence (ABC) scales.

Thus, the objective of the current study was to evaluate the independence, confidence and balance in the development of daily activities in patients with PD before and after rehabilitation.

\section{Methods}

\section{Participants and Study Design}

This study was approved by the Research Ethics Committee (Plataforma Brasil)-opinion number 832.502/2014, and authorized by the patients, who signed the Free Informed Consent Form. The study follows the principles of the Declaration of Helsinki.

A descriptive, retrospective cross-sectional study was carried out. The sample included 16 patients ( 6 female and 10 male) with PD who were referred by the department of neurology from the clinical hospital for assessment in the department of otoneurology of a teaching institution in the same city. The diagnosis of PD was held according to the Queen Square Brain Bank criteria. The mean age of the patients was between 18 and 82 years (mean $57.5 \pm 18.7$ years). The mean disease duration was $5.1 \pm 3.2$ ( 1 year, and 11 years maximum).

Adult patients with PD, not diagnosed with middle-ear disorders, no use of walking devices, and not formerly submitted to any rehabilitation therapy were included in the study. Patients with ear disorders, incapable of complying with and understanding simple verbal commands, and visually impaired were excluded.

All patients underwent otorhinolaryngological assessment, anamnesis and vestibular system screening with digital vector electronystagmography (VENG), which has its own software VecWin2 (Neurograff Eletromedicina LTDA, São Paulo, SP, Brazil), a rotating chair model COD 14200 , rotation 0.01 to $0.5 \mathrm{~Hz}$, (Cadeiras Ferrante Ltda, São Paulo, SP, Brazil), a visual stimulator model EV VEC (Neurograff Eletromedicina LTDA, São Paulo, SP, Brazil), and an air caloric stimulator model NGR 05 (Neurograff Eletromedicina LTDA, São Paulo, SP, Brazil). The flow rate used was 5 and $13 \mathrm{~L} / \mathrm{min}$.

Subsequently, the $\operatorname{VADL}^{10}$ and the $\mathrm{ABC}^{11}$ questionnaires were applied. They were applied before rehabilitation ( $1^{\text {st }}$ assessment) and after the $20^{\text {th }}$ session of rehabilitation ( $2^{\text {nd }}$ assessment), aiming at observing the prospective postintervention changes.

Vestibular Disorders Activities of Daily Living Scale (VADL) - culturally adapted to the Brazilian population by Aratani et al, ${ }^{10}$ it assesses the dependence and the impact of body imbalance on the performance of daily activities. The questionnaire includes 28 daily living activities divided into three subscales, functional (12 activities), ambulation (9 activities), and instrumental (7 activities). Using a qualitative scale, the patients are assigned 0 to 10 points according to their performance and independence in performing each described activity. The score is calculated from the median of values, in which the higher the score the higher the dependence and inability of the patient. For "Not Applicable" (N/A) answers, that is, the patient does not perform the activity or does not want to reply, the question is given zero points.

Activities-specific Balance Confidence Scale (ABC) culturally adapted to the Brazilian population by Marques et $\mathrm{al}^{11}{ }^{11}$ it assesses the level of confidence of the individual in the ability to maintain balance while performing specific daily activities. The questionnaire comprises 16 questions on how confident subjects are to carry out a certain activity (not confident $=0 \%$, and completely confident to carry out the activity without losing balance $=100 \%$ ). Therefore, the higher the percentage, the greater their self-confidence.

\section{Vestibular Rehabilitation with Virtual Reality (VR)}

The exercises aim to improve the vestibulo-visual interaction during head movements, to increase static and dynamic postural stability under conditions that produce conflicting sensory information, to improve the ability in performing daily activities, and to provide patients with greater physical independence. $^{8}$ 
Vestibular rehabilitation with VR is a therapeutic method used in body-balance rehabilitation. Nintendo Wii equipment, Wii remote e Wii balance Board (Nintendo Co, Ltd., Kyoto, Japan) were used. This platform measures the applied strength, and records slight balance changes by means of pressure sensors. At first, patients got familiar with the game and were instructed regarding the necessary movements to play it. The Wii balance board entails reactive and proactive strategies of postural control by means of visual feedback as well as the challenge for better performance in order to finish the games.

Four balance games were carried out (soccer heading, table tilt, tightrope walk e ski slalom) with strategies involving saccadic, optokinetic stimuli, head movement, static and dynamic balance, motor coordination, eye-pedal coordination, circular pelvis movements, knee flexion-extension, ankle-hip movements, back to front and side to side movements and weight transfer, aiming at balance disorders and postural instability.

All patients carried out 20 VR sessions individually, 50 minutes each ( 10 minutes of heating exercises and 40 minutes of balance exercises), twice a week, and were submitted to the same assessing questionnaires before and after the end of the rehabilitation sessions. The patients performed this type of intervention exclusively with games and were not oriented to perform any type of complementary traditional exercise at home.

\section{Statistical Analysis}

Data analyses were held by means of descriptive statistics, Friedman analysis of variance (ANOVA), Spearman Correlation Coefficient and paired Student $t$-test at a significance level of 0.05 [(5\%) by means of the Statistica 13.1 software
Table 1 Symptoms in patients with Parkinson disease $(n=16)$

\begin{tabular}{|l|l|l|}
\hline SYMPTOMS & $\mathbf{n}$ & $\%$ \\
\hline Tremor & 12 & 75.0 \\
\hline Muscle stiffness & 12 & 75.0 \\
\hline Imbalance & 10 & 62.5 \\
\hline Difficulty walking & 7 & 43.7 \\
\hline Dizziness & 7 & 43.7 \\
\hline Dysphagia & 6 & 37.5 \\
\hline Paresthesia & 3 & 18.7 \\
\hline Tinnitus & 2 & 12.5 \\
\hline Dysarthria & 2 & 12.5 \\
\hline Headache & 1 & 6.2 \\
\hline Tiredness when speaking & 1 & 6.2 \\
\hline
\end{tabular}

Abbreviation: $\mathrm{n}$, number; PD, Parkinson disease.

(StatSoft, Inc., Tulsa, OK, USA). For the tests, the 95\% confidence interval $(\mathrm{CI})$ was applied.

\section{Results}

The most reported complaints during the anamnesis were: tremor and muscle stiffness (75\% each), imbalance (62.5\%), difficulty in gait and dizziness (43.7\% each), as shown in table 1.

Disorders in the vestibular testing were evidenced in 5 cases (31.2\%), with 3 cases (18.7\%) of peripheral vestibular deficit dysfunction and 2 cases (12.5\%) of hyperreflexia/vestibular dysfunction. Testing results were normal in 11 cases (68.8\%). Results of the VADL questionnaire can be observed in table 2 .

Table 2 Results of the Vestibular Disorders Activities of Daily Living questionnaire and according to subscales and general assessment $(n=16)$

\begin{tabular}{|c|c|c|c|c|c|c|c|}
\hline \multirow[t]{2}{*}{ ASSESSMENT } & \multicolumn{5}{|c|}{ DESCRIPTIVE STATISTICS } & \multirow[t]{2}{*}{$p$} & \multirow[t]{2}{*}{$95 \% \mathrm{Cl}$} \\
\hline & MEAN & MEDIAN & MIN & MAX & SD & & \\
\hline \multicolumn{8}{|l|}{ FUNCTIONAL } \\
\hline 1st assessment & 1.69 & 1.42 & 0.92 & 4.42 & 1.00 & \multirow[t]{2}{*}{0.240} & \multirow[t]{2}{*}{$-0.43 ; 0.81$} \\
\hline 2nd assessment & 1.50 & 1.29 & 0.92 & 3.50 & 0.69 & & \\
\hline \multicolumn{8}{|l|}{ AMBULATION } \\
\hline 1st assessment & 2.11 & 1.27 & 1.00 & 6.73 & 1.82 & \multirow[t]{2}{*}{0.225} & \multirow[t]{2}{*}{$-0.71 ; 0.73$} \\
\hline 2nd assessment & 2.10 & 1.44 & 1.00 & 6.89 & 1.87 & & \\
\hline \multicolumn{8}{|l|}{ INSTRUMENTAL } \\
\hline 1st assessment & 3.63 & 3.50 & 1.00 & 8.20 & 2.49 & \multirow[t]{2}{*}{0.022} & \multirow[t]{2}{*}{$1.21 ; 2.21$} \\
\hline 2nd assessment & 1.92 & 1.36 & 0.57 & 4.43 & 1.20 & & \\
\hline \multicolumn{8}{|l|}{ GENERAL } \\
\hline 1st assessment & 2.23 & 1.64 & 1.18 & 5.57 & 1.27 & \multirow[t]{2}{*}{0.054} & \multirow[t]{2}{*}{$-0.36 ; 1.30$} \\
\hline 2nd assessment & 1.76 & 1.42 & 1.07 & 4.40 & 1.03 & & \\
\hline
\end{tabular}

Abbreviation: $\mathrm{Cl}$, confidence interval; Max, maximum; Min, minimum; SD, standard deviation; VADL, Vestibular Disorders Activities of Daily Living. Significant $p$ values are in bold.

*Friedman analysis of variance (ANOVA) test. 
Table 3 Results of the Activities-Specific Balance Confidence questionnaire $(n=16)$

\begin{tabular}{|l|l|l|l|l|l|l|l|}
\hline \multirow{2}{*}{ ASSESSMENT } & \multicolumn{4}{l|}{ DESCRIPTIVE STATISTICS } & & \\
\cline { 2 - 6 } & MEAN & MEDIAN & MIN & MAX & SD & $P$ & $95 \%$ CI \\
\hline 1st assessment & 74.79 & 80.94 & 27.50 & 100.00 & 20.59 & 0.459 & $-18.27 ;-10.35$ \\
\hline 2nd assessment & 78.75 & 89.38 & 31.25 & 97.50 & 19.05 & & \\
\hline
\end{tabular}

Abbreviations: ABC, Activities-Specific Balance Confidence; $\mathrm{Cl}$, confidence interval; Min, minimum; Max, maximum; SD, standard deviation.

${ }^{*}$ Friedman analysis of variance (ANOVA) test.

The application of the Friedman ANOVA test showed no statistically significant difference for the subscales: Functional ( $p=0.240,95 \% \mathrm{CI}$ from $-0.43-0.81)$ and ambulation $(p=0.225,95 \% \mathrm{CI}$ from $-0.71-0.73)$. The instrumental subscale evidenced statistically significant difference $(p=0.022$, $95 \% \mathrm{Cl}$ from $1.21-2.21$ ) between the $1^{\text {st }}$ and $2^{\text {nd }}$ assessments. For the general assessment, there was also no significant difference ( $p=0.054,95 \% \mathrm{CI}$ from $-0.36-1.30)$. The results of the $A B C$ questionnaire are shown in - Table 3.

The application of the Friedman ANOVA test showed no significant difference between the scoring of both assessments ( $p=0.459,95 \% \mathrm{CI}$ from -18.27 to -10.35 ).

The correlation result between the VADL and ABC questionnaires can be seen in table 4 .

The application of the Spearman correlation coefficient evidenced significant correlation $(p=0.011,95 \%$ CI from -0.85 to -0.17$)(p=0.002,95 \% \mathrm{CI}$ from -0.88 to -0.31$)$ between the VADL and ABC questionnaires for the ambulation subscale in both assessments, while for the functional subscale, correlation was only verified in the $2^{\text {nd }}$ assessment $(p=0.011,95 \% \mathrm{CI}$ from -0.85 to -0.17$)$. For the instrumental subscale, there was no significant correlation in any assessments. For the general assessment, there was a statistically significant correlation $(p=0.010,95 \%$ CI from -0.85 to -0.18 ) in the $1^{\text {st }}$ assessment. As the correlation coefficient always resulted negative, it was evidenced an inverse correlation between the questionnaires, that is, the lowest scores in the VADL questionnaire correspond to the highest scores in the $A B C$ questionnaire, thus evidencing that the best results in the VADL questionnaire correspond to the best results in the $\mathrm{ABC}$ questionnaire. As for the subscales, the highest correlations occurred in the ambulatory subscale.

The correlation between age and disease duration according to the VADL and $A B C$ questionnaires can be observed in table 5.

The application of the Spearman correlation coefficient revealed no significant correlation between disease duration according to the VADL and $A B C$ questionnaires in any assessments.

The result of virtual games ( $1^{\text {st }}$ assessment $)$ and $\left(2^{\text {st }}\right.$ assessment is show in table 6).

The Student $t$-test evidenced a statistically significant difference between the tightrope walk $(p=0.034,95 \% \mathrm{CI}$ from -12.5 to -0.3$)$ and the ski slalom $(p=0.005,95 \% \mathrm{CI}$ from -34.8 to -6.6 ) games, showing that these games were more efficient for this type of population than the other games used along the therapeutic intervention. Patients reported that the improvement was reflected in their daily activities.

\section{Discussion}

Gait and balance impairments are common symptoms of PD. Such motor symptoms are debilitating, leading to the decline of the patients in their self-perception and balance confidence. ${ }^{12-14}$ The reduction in the ability to walk, as well as the postural instability have been identified as causes for the fear of falling and reduced mobility, with consequent reduction in the QOL of subjects with PD. Studies $3,15,16$ observed gait difficulty in $83 \%$ of individuals, expressed

Table 4 Correlation between the Vestibular Disorders Activities of Daily Living and Activities-Specific Balance Confidence questionnaires $(n=16)$

\begin{tabular}{|l|l|l|l|}
\hline RESULT & $\boldsymbol{r}_{s}$ & $\boldsymbol{p}$ & $\mathbf{9 5 \%} \mathrm{Cl}$ \\
\hline VADL functional and ABC - 1st assessment & -0.3205 & 0.226 & $-0.70 ; 0.21$ \\
\hline VADL ambulation and ABC - 1st assessment & -0.6113 & $\mathbf{0 . 0 1 1}$ & $-0.85 ;-0.17$ \\
\hline VADL instrumental and ABC - 1st assessment & -0.4598 & 0.073 & $-0.78 ; 0.05$ \\
\hline VADL general and ABC - 1st assessment & -0.6187 & $\mathbf{0 . 0 1 0}$ & $-0.85 ;-0.18$ \\
\hline VADL functional and ABC - 2nd assessment & -0.6113 & $\mathbf{0 . 0 1 1}$ & $-0.85 ;-0.17$ \\
\hline VADL ambulation and ABC - 2nd assessment & -0.6983 & $\mathbf{0 . 0 0 2}$ & $-0.88 ;-0.31$ \\
\hline VADL instrumental and ABC - 2nd assessment & -0.2369 & 0.377 & $-0.66 ; 0.29$ \\
\hline VADL general and ABC - 2nd assessment & -0.4423 & 0.086 & $-0.77 ; 0.07$ \\
\hline
\end{tabular}

Abbreviation: VADL: Vestibular Disorders Activities of Daily Living; ABC: Activities-Specific Balance Confidence; CI: confidence interval. Significant $p$ values are in bold.

${ }^{*} r_{s}$ test. 
Table 5 Correlation between duration of the disease according to the Vestibular Disorders Activities of Daily Living and ActivitiesSpecific Balance Confidence questionnaires $(n=16)$

\begin{tabular}{|l|l|l|l|}
\hline \multirow{2}{*}{ RESULT } & \multicolumn{2}{l|}{ DURATION OF THE DISEASE } & \multirow{2}{*}{$95 \% \mathrm{CI}$} \\
\cline { 2 - 4 } & $\boldsymbol{r}_{\mathbf{s}}$ & $\boldsymbol{P}$ & \\
\hline VADL functional - 1st assessment & 0.4677 & 0.067 & $-0.04 ; 0.78$ \\
\hline VADL functional - 2nd assessment & 0.2015 & 0.454 & $-0.33 ; 0.63$ \\
\hline VADL ambulation - 1st assessment & 0.2050 & 0.446 & $0.32 ; 0.64$ \\
\hline VADL ambulation - 2nd assessment & 0.1999 & 0.458 & $-0.33 ; 0.63$ \\
\hline VADL instrumental - 1st assessment & 0.1167 & 0.666 & $-0.40 ; 0.58$ \\
\hline VADL instrumental - 2nd assessment & 0.0598 & 0.825 & $-0.45 ; 0.54$ \\
\hline VADL general - 1st assessment & 0.1909 & 0.478 & $-0.34 ; 0.63$ \\
\hline VADL general - 2nd assessment & 0.1232 & 0.649 & $-0.40 ; 0.58$ \\
\hline ABC - 1st assessment & 0.1171 & 0.665 & $-0.40 ; 0.58$ \\
\hline ABC - 2nd assessment & -0.4242 & 0.101 & $-0.76 ; 0.09$ \\
\hline
\end{tabular}

Abbreviation: ABC, Activities-Specific Balance Confidence; Cl, confidence interval; VADL, Vestibular Disorders Activities of Daily Living. ${ }^{*} r_{s}$ test.

by slowness and shortening of steps, difficulty in beginning the gait and balance deficit. Authors stated that those disabilities occur due to improper functioning of the basal ganglia to perform muscle adjustments during locomotion, thus leading to freezing episodes and increase in the double-support phase, that is, the period of greater gait stability. Knowingly, motor symptoms precede disability; therefore, physical aspects are pivotal for worsening the QOL of subjects suffering from PD. These results are consistent with our findings.

Mhatre et $\mathrm{al}^{2}$ claim that impairments in balance and postural stability contribute to increase the risk of falls and fractures in this population. Falls are a major health problem among the elderly population. The brain needs to process signals from the visual, vestibular and somatosensory systems to maintain postural stability. ${ }^{17,18}$ The combined loss of sensory signals has been pointed as a major cause of imbalance. ${ }^{18}$ As a consequence, the elderly population develops the fear of falls, reduces their self-confidence to carry out ADLs, and end up adopting a less active lifestyle. ${ }^{19}$

The tests that make up the vestibular exam allow us to evaluate the relationship between balance and posterior labyrinth function, vestibular branches of the VIII cranial nerve, vestibular nuclei of the floor of the fourth ventricle, vestibular pathways and, above all, the vestibulo-oculomotor, vestibulocerebellar, vestibulo-spinal and cervico-vestibular proprioception interrelationships. The authors ${ }^{20,21}$ point to the prevalence of peripheral vestibular alterations in the elderly. The authors ${ }^{22}$ evaluated 30 Parkinsonian patients and reported 25 abnormal exams (23 cases with peripheral vestibular alterations and two cases with central vestibular alterations) and 5 cases within the normal limits. The fact that we do not observe a relevant number of central vestibular alterations in PD is due to the disease stage of the patients.

Concerning the application of the VADL questionnaire was statistically significant $(p<0.05)$ was observed for the instrumental subscale. Patients with PD have greater risk to reduce their ADLs with the progression of the disease, particularly activities demanding coordination, balance and mobility, ${ }^{23,24}$ thus causing them dependence and the consequent negative impact on their QOL. ${ }^{25,26}$ The concept of QOL is highly complex and refers to the perception of the subjects regarding their disease and its effect on their lives, involving personal satisfaction associated with their physical, functional, emotional and social well-being. In the context of chronic diseases, the maintenance of QOL must be one of the treatment concerns. ${ }^{13}$

Table 6 Virtual reality game performance $(n=16)$

\begin{tabular}{|l|l|l|l|l|l|l|}
\hline \multirow{2}{*}{ GAME } & \multicolumn{2}{|l|}{ SESSION 1 } & \multicolumn{2}{l|}{ SESSION 20 } & \multirow{2}{*}{ 95\% CI } \\
\cline { 2 - 5 } & MEAN & SD & MEAN & SD & & \\
\hline Soccer heading & 27.7 & 18.6 & 42.3 & 25.0 & 0.112 & $-30.5 ; 1.3$ \\
\hline Tightrope walk & 19.3 & 6.1 & 25.7 & 10.4 & $\mathbf{0 . 0 3 4}$ & $-12.5 ;-0.3$ \\
\hline Table tilt & 73.3 & 14.5 & 66.1 & 18.8 & 0.162 & $-4.9 ; 19.3$ \\
\hline Ski slalom & 34.6 & 8.8 & 55.3 & 26.2 & $\mathbf{0 . 0 0 5}$ & $-34.8 ;-6.6$ \\
\hline
\end{tabular}

Abbreviation: $\mathrm{Cl}$, confidence interval; SD, standard deviation.

Significant $p$ values are in bold.

*Student $t$-test. 
The correlation between the ABC and VADL questionnaires was statistically significant $(p<0.05)$ in both assessments for the ambulation subscale, which assesses the perception of mobility-related abilities, while for the functional subscale, which assesses the individual perception of basic self-maintenance activities, significance was evidenced in the $2^{\text {nd }}$ assessment. In the general assessment, there was significant correlation in the $1^{\text {st }}$ assessment. Corroborating our findings, Cohen ${ }^{9}$ reported that imbalance may hinder the performance of daily activities, such as those that demand fast head motion, as well as tasks demanding trunk and head flexion.

The authors ${ }^{27}$ assessed 104 subjects with idiopathic PD (averaging 66.5 years old, disease duration of 8.8 years) and observed that there was strong correlation to turning and gait measures related to rhythm and dynamic stability during the gait in the $A B C$ questionnaire. In addition, there were poor correlations between the $\mathrm{ABC}$ questionnaire and postural sway in an upright, standing position. The study evidenced coherence in the correlation patterns (that is, the severity of the disease as well as patients' perception of their mobility impairment were related to the same objective mobility measures). Corroborating our findings, Bryant et $\mathrm{al}{ }^{16}$ reported striking differences in the walking speed, stride length during backward and forward gait and 360 degree turn among individuals with PD who feared falls. The study provided better understanding for the relation between balance and gait measures and patients perceived impaired mobility. Detailed understanding on how neurological disorders cause balance and gait dysfunction, which affect patients' lives and are related to the disease severity, will be helpful to orient rehabilitation interventions, that is, improvement in the turning speed, gait speed and stride length. The authors ${ }^{5}$ report that a wide range of subjective and objective assessments have been used to assess balance in subjects with PD. However, little is known on the relation between self-perception and balance confidence. Authors ${ }^{15}$ applied the $A B C$ questionnaire to 44 individuals after the performance of static and dynamic balance tasks. The center of pressure and the center of mass were calculated and the severity of the disease was observed to influence confidence relations and control of the static and dynamic balance.

Regarding the exergames used, we observed, with the application of the VADL and ABC questionnaires before and after 20 rehabilitation sessions, the improvement in the independence, confidence, and balance with tightrope walk and ski slalom games, showing that such games were more efficient for this type of population than the other games played. Canning et $\mathrm{al}^{28}$ carried out exercises with 231 subjects suffering from PD for 6 months, 3 times a week, 40 to 60 minutes each session, and reported that lower-limb balance and strength exercises may not only improve balance and gait but also enhance the confidence and QOL of the patients. Zettergren et a ${ }^{29}$ observed Nintendo WiiFit-related benefits. These benefits include an increase in patients' adherence to the exercises, improvement in the social interaction and self-esteem. The authors ${ }^{30}$ analyzed the use of dancing for balance and mobility training, and found im- provement in balance and mobility in 20 sessions for $10 / 13$ weeks. In animal trials, Petzinger et $\mathrm{al}^{31}$ showed that exercising may alter dopaminergic neurotransmission. Studies ${ }^{32}$ have pointed that patients' participation in training programs has proved efficient to reduce depression, falls, fatigue, thus improving their QOL. By applying the $A B C$ questionnaire before and after the training, Mhatre et $\mathrm{al}^{2}$ and Acarer et $\mathrm{al}^{33}$ reported that patients with PD evidenced stiffness reduction, balance improvement, reduction in the postural sway and better QOL, corroborating our findings.

The authors of the present study suggest for future studies the inclusion of Vestibular Evoked Myogenic Potential (VEMP), which, associated with functional tests, may improve/complement the findings of subjective tests.

\section{Conclusion}

Our results showed that the VADL and ABC questionnaires, applied before and after the rehabilitation training, were major tools to measure independence, confidence, and balance in the development of daily activities.

The VADL and ABC questionnaires may effectively contribute to quantify the effect of the applied therapeutics and, consequently, its impact on the QOL of patients with PD.

\section{Funding}

This work was supported by the Coordenação de Aperfeiçoamento de Pessoal de Nível Superior - Brazil (CAPES) under grant number 001 .

\section{Conflict of Interests}

The authors have no conflict of interests to declare.

The authors M. I. R. S. and G. J. B. S. performed data collection, tabulation, and literature review; J. M. M. performed statistical analysis and literature review; $\mathrm{H}$. A. G. T., J. S. M., M. R. J., M. R. R., P. B. N. L. and R. S. S. performed manuscript writing and final revision; and B.S. Z. was responsible for the project and study design in addition to general supervision of the performance steps and manuscript elaboration.

\section{References}

1 Andrade LAF, Barbosa ER, Cardoso F, Teive HAG. Parkinson's disease: Current treatment strategies. São Paulo: Lemos Editorial; 1999

2 Mhatre PV, Vilares I, Stibb SM, et al. Wii Fit balance board playing improves balance and gait in Parkinson disease. PM R 2013;5(09): 769-777

3 Silva PFC, Pereira RPR, Silva SM, Corrêa JCF, Corrêa FI. Correlation between clinical profile, quality of life and disability of the patients of Associação Brasil Parkinson. ConsScientiare Saúde 2011;10(04):650-656

4 Jankovic J. Parkinson's disease: clinical features and diagnosis. J Neurol Neurosurg Psychiatry 2008;79(04):368-376

5 Lee HK, Altmann LJ, McFarland N, Hass CJ. The relationship between balance confidence and control in individuals with Parkinson's disease. Parkinsonism Relat Disord 2016;26:24-28

6 Zeigelboim BS, Jurkiewicz AL, Fukuda Y, Mangabeira-Albernaz PL. Vestibular alterations in degenerative diseases of the central nervous system. Pro Fono 2001;13:263-270 
7 Smiley-Oyen AL, Cheng HY, Latt LD, Redfern MS. Adaptation of vibration-induced postural sway in individuals with Parkinson's disease. Gait Posture 2002;16(02):188-197

8 Herdman SJ. Vestibular rehabilitation. Curr Opin Neurol 2013;26 (01):96-101

9 Cohen H. Vestibular rehabilitation improves daily life function. Am J Occup Ther 1994;48(10):919-925

10 Aratani MC, Ricci NA, Caovilla HH, Ganança FF. Brazilian version of the Vestibular Disorders Activities of Daily Living Scale (VADL). Rev Bras Otorrinolaringol (Engl Ed) 2013;79(02):203-211

11 Marques AP, Mendes YC, Taddei U, Pereira CA, Assumpção A. Brazilian-Portuguese translation and cross cultural adaptation of the activities-specific balance confidence (ABC) scale. Braz J Phys Ther 2013;17(02):170-178

12 Kim S, Horak FB, Carlson-Kuhta P, Park S. Postural feedback scaling deficits in Parkinson's disease. J Neurophysiol 2009;102(05): 2910-2920

13 Schrag A, Jahanshahi M, Quinn N. How does Parkinson's disease affect quality of life? A comparison with quality of life in the general population. Mov Disord 2000;15(06):1112-1118

14 Adkin AL, Frank JS, Jog MS. Fear of falling and postural control in Parkinson's disease. Mov Disord 2003;18(05):496-502

15 Ellis T, Cavanaugh JT, Earhart GM, Ford MP, Foreman KB, Dibble LE. Which measures of physical function and motor impairment best predict quality of life in Parkinson's disease? Parkinsonism Relat Disord 2011;17(09):693-697

16 Bryant MS, Rintala DH, Hou JG, Protas EJ. Influence of fear of falling on gait and balance in Parkinson's disease. Disabil Rehabil 2014;36(09):744-748

17 Herman T, Giladi N, Gruendlinger L, Hausdorff JM. Six weeks of intensive treadmill training improves gait and quality of life in patients with Parkinson's disease: a pilot study. Arch Phys Med Rehabil 2007;88(09):1154-1158

18 Müjdeci B, Aksoy S, Atas A. Evaluation of balance in fallers and non-fallers elderly. Rev Bras Otorrinolaringol (Engl Ed) 2012;78 (05):104-109

19 Wolfson L, Judge J, Whipple R, King M. Strength is a major factor in balance, gait, and the occurrence of falls. J Gerontol A Biol Sci Med Sci 1995;50(Spec No):64-67

20 Gushikem P, Caovilla HH, Ganança MM. Avaliação otoneurológica em idosos com tontura. Acta Awho. 2002;21(01):1-25
21 Mota PHM, Franco ES, Monteiro Pinto ES, Arieta AM. Estudo do equilíbrio no idoso por meio da electronistagmografia. Acta Awho. 2002;21(03):1-12

22 Martins Bassetto J, Zeigelboim BS, Jurkiewicz AL, Klagenberg KF. Achados otoneurológicos em pacientes com doença de Parkinson. Rev Bras Otorrinolaringol 2008;74:350-355

23 Jankovic J, Kapadia AS. Functional decline in Parkinson disease. Arch Neurol 2001;58(10):1611-1615

24 Shulman LM, Gruber-Baldini AL, Anderson KE, et al. The evolution of disability in Parkinson disease. Mov Disord 2000;15:1112-1118

25 Volpe D, Giantin MG, Manuela P, et al. Water-based vs. non-waterbased physiotherapy for rehabilitation of postural deformities in Parkinson's disease: a randomized controlled pilot study. Clin Rehabil 2017;31(08):1107-1115

26 Atterbury EM, Welman KE. Balance training in individuals with Parkinson's disease: Therapist-supervised vs. home-based exercise programme. Gait Posture 2017;55:138-144

27 Curtze C, Nutt JG, Carlson-Kuhta P, Mancini M, Horak FB. Objective gait and balance impairments relate to balance confidence and perceived mobility in people with Parkinson disease. Phys Ther 2016;96(11):1734-1743

28 Canning CG, Sherrington C, Lord SR, et al. Exercise for falls prevention in Parkinson disease: a randomized controlled trial. Neurology 2015;84(03):304-312

29 Zettergren K, Franca J, Antunes M, Lavallee C. The effects of Nintendo Wii Fit training on gait speed, balance, functional mobility and depression in one person with Parkinson's disease. ATI 2011;5(02):38-44

30 Marchant D, Sylvester JL, Earhart GM. Effects of a short duration, high dose contact improvisation dance workshop on Parkinson disease: a pilot study. Complement Ther Med 2010;18(05):184-190

31 Petzinger GM, Walsh JP, Akopian G, et al. Effects of treadmill exercise on dopaminergic transmission in the 1-methyl-4-phenyl-1,2,3,6-tetrahydropyridine-lesioned mouse model of basal ganglia injury. J Neurosci 2007;27(20):5291-5300

32 Lin MR, Wolf SL, Hwang HF, Gong SY, Chen CY. A randomized, controlled trial of fall prevention programs and quality of life in older fallers. J Am Geriatr Soc 2007;55(04):499-506

33 Acarer A, Karapolat H, Celebisoy N, Ozgen G, Colakoglu Z. Is customized vestibular rehabilitation effective in patients with Parkinson's? NeuroRehabilitation 2015;37(02):255-262 